\title{
Article \\ Social Exclusion/Inclusion for Urban Aboriginal and Torres Strait Islander People
}

\author{
Maggie Walter \\ School of Social Sciences, University of Tasmania, Hobart, TAS 7001, Australia; E-Mail: maggie.walter@utas.edu.au
}

Submitted: 4 September 2015 | Accepted: 22 January 2016 | Published: 23 February 2016

\begin{abstract}
Social exclusion social inclusion are useful concepts for making sense of the deeply embedded socio-economic disadvantaged position of Aboriginal and Torres Islander people in Australian. The concepts not only describe exclusion from social and economic participation; but seek to understand the dynamic processes behind their creation and reproduction. Yet few Australian studies go beyond describing Aboriginal over-representation on social exclusion indicators. Neither do they address the translatability of the concepts from non-Indigenous to Indigenous contexts despite mainstream studies finding the pattern of social exclusion (and therefore what social inclusion might look like) differs for Aboriginal and Torres Strait Islander people to that of other disadvantaged groups. This paper uses data from the Longitudinal Study of Indigenous children to explore patterns of social exclusion across social, economic, well-being and community dimensions for urban Aboriginal and Torres Strait families. The paper then develops a contextual understanding of the processes and patterns that create and sustain social exclusion and the opportunities and challenges of moving to greater social inclusion for urban Aboriginal and Torres Strait Islander people/s.
\end{abstract}

\section{Keywords}

aboriginal; social exclusion; social inclusion; Torres Strait Islander

\section{Issue}

This article is part of the issue "Social Inclusion and Indigenous Peoples", edited by Pat Dudgeon (University of Western Australia, Australia), Waikaremoana Waitoki (University of Waikato, New Zealand), Rose LeMay (Wharerātā Group, Canada) and Linda Waimarie Nikora (University of Waikato, New Zealand).

(C) 2016 by the authors; licensee Cogitatio (Lisbon, Portugal). This article is licensed under a Creative Commons Attribution 4.0 International License (CC BY).

\section{Introduction}

The concepts of social exclusion and its policy ambition, social inclusion, are directly applicable to making sense of the longstanding marginalisation of Aboriginal and Torres Islander people within Australian society. These concepts extend our understanding of Aboriginal and Torres Strait Islander's people's position as being much more than economic disadvantage. Social exclusion not only describes exclusion from social and economic participation, but seeks to understand the dynamic processes behind their creation and reproduction. The complexity and multidimensional nature of social exclusion, therefore, is inclusive of negative social participatory aspects and the diminished citizenship that is inherent in, and compounded by, exclusion from social resources. Yet, gaining a greater understanding of Aboriginal and Torres Strait Islander positioning is more than translating the concepts from non-Indigenous to Indigenous contexts. What little work exists on the topic (see Hunter, 2009) suggests that the concepts of social inclusion and exclusion for Indigenous peoples have complexities not found in their application to dominant White settler populations. The dearth of theoretically informed literature also raises questions of the pattern of Indigenous social exclusion (and therefore what social inclusion) might look like.

This paper uses data from the Longitudinal Study of Indigenous children (LSIC) to explore patterns of social exclusion across social, economic, community and wellbeing dimensions for urban Aboriginal and Torres Strait families. This study, while using the study child as the 
unit of analysis, contains a wealth of data pertaining to family and parent circumstances and lived realities. The paper then uses these results to inform a contextual discussion of the processes and patterns that create and sustain social exclusion and the opportunities and challenges of moving to greater Indigenous social inclusion. The geographic terms used in this analysis are based on the index of Level of Relative Isolation which has five categories of isolation. Areas defined as having no level of isolations ('None') are metropolitan areas; those defined as having low levels of isolation are small cities or large towns. 'Moderate' refers to smaller towns located a significant distance from the nearest city and 'High' and 'Extreme' refers to small communities, often discrete Indigenous communities, situated in remote parts of Australia, a long distance from any urban areas (Department of Families, Housing, Community Services and Indigenous Affairs, 2011).

The study is confined to urban and regional families ('None' and 'Low' levels of relative isolation). The LSIC sample is divided because the contexts of social and community participation for Aboriginal and Torres Strait Islander people living in urban centres, and those living in remote areas of Australia are not directly comparable. Life circumstance similarities for respondents from 'None' and 'Low' level of relative isolation localities include that life is lived within a dominant non-Indigenous social and cultural setting. Levels of Relative Isolation are a proxy for the proportion of Indigenous and nonIndigenous population in a location. Indigenous people in areas defined as 'None' or 'Low' relative isolation are likely to make up just two to three percent of the total population of those areas. Conversely, those living in areas defined as 'High' and 'Extreme' are likely to be living in locations where the large majority of the population are Aboriginal or Torres Strait Islander people. The other reason for exploring urban and regional families separately is that most current statistics on Aboriginal and Torres Strait Islander people are presented at state or national aggregates, despite the very different life circumstances across geographic areas. As a result the actualities of social exclusion for urban/regional populations are rarely explored separately and social exclusion among Aboriginal and Torres Strait Islander families living in cities and regional towns is under-researched.

\section{Social Exclusion and Aboriginal and Torres Strait Islander People}

Social exclusion refers to the exclusion of people or groups from participation in mainstream social and economic life. In doing so the concept recognises the social aspects of poverty as well as the power relationship dimensions. As Burchardt, Le Grand and Piachaud (2002) argue, the exclusion of some groups from social resources support the privileged position of other groups. In turn, this distribution of social resources is re- inforced by how those socially excluded interact with their wider society, and wider society with them. In this way social exclusion, includes the social processes involved in the underlying causes of poverty and inequality as well as outcomes (Fincher \& Saunders, 2001, p. 9). As Sen (2000) argues, the helpfulness of the concept of social exclusion, is in its focussing attention on the role of the social and relational dimensions of deprivation.

One issue complicating the measuring of social exclusion is the complexity of the concepts. Many researchers, therefore, have argued it is more useful to develop a general conception of social exclusion rather than pursue a precise definition (Bradshaw, 2003; Burchardt et al., 2002; Saunders, 2003). Lister (2004), for example, states that social exclusion can be most usefully understood and used as a multifocal lens that illuminates aspects of poverty. The multidimensional nature of exclusion also translates to a wide array of potential elements to be included and this variety is reflected in the varying research constructions of the concept. Gordon et al. (2000), for example, identifies four dimension of social exclusion: income below poverty income threshold; labour market exclusion, service exclusion; and exclusion from social relations. Similarly, the Brotherhood of St Laurence, in collaboration with the Melbourne Institute of Applied Economic and Social Research, developed a social exclusion measure drawing on seven domains (BSL-MIAESR) (Azpitarte \& Bowman, 2015). This multi-dimensional index includes measures of: material resources; employment; education and skills; health and disability; social connection; community and personal safety. Regardless of items included, however, such measures must always encompass the basic idea that social exclusion is both multi-dimensional concept and that it is clustered among vulnerable groups rather than evenly experienced across the broader population.

Social exclusion and social inclusion, by definition, are contextual, locational and situational. The form that social exclusion takes, the groups that are most vulnerable to that form of social exclusion, and the social inclusion measures needed to address the social exclusion, are particular to the society and the location and times in which they are found. These central aspects of social exclusion are particularly salient for Aboriginal and Torres Strait Islander people. Consistently identified in the literature as over-represented on measures social exclusion (see Brotherhood of St Laurence, 2015; Saunders, Naidoo, \& Griffiths, 2007) there is, however, little literature that specifically addresses the Aboriginal dimensions of social exclusion or social inclusion. What literature does exist, such as the Overcoming Indigenous Disadvantage Key Indicators (Steering Committee for the Review of Government Service Provision, 2014) report from the Productivity Commission tend to explore social exclusion as a set of measures rather than as a concept that has structural foundations. Yet, social exclusion is a 
social, not individual, phenomenon, informed by patterns that emerge from examining linked social problems (Lister, 2004; Sen, 2000). As Saunders (2003, p. 5) argues, viewed as an individual attribute, social exclusion can become 'a vehicle for vilifying those who do not conform and an excuse for seeing their problems as caused by their own "aberrant behaviour'. Rather, as per Sen (2000), social exclusion might be better seen as capability deprivation with capability conceptualised as a reflection of the freedom to achieve core functionings such as being healthy, having a good job, safety and self respect. The restriction of capability limits or denies the ability of the individual, or groups of individuals to achieve outcomes that are valued and have reason to be valued; to achieve what Sen labels 'a decent life'.

The mainstream literature on social exclusion/inclusion is informative, but the validity of transposing of the understandings, strategies and policies from one place, or one population, to another is questionable. Hunter (2009) argues that the translatability of social exclusion and social inclusion from nonIndigenous to Indigenous contexts is problematic. Yet the conceptualisation of social exclusion implicit in the Overcoming Indigenous Disadvantage framework based on exclusion from the mainstream norm. There are no Indigenous specific indicators and the definition of social exclusion and the measurement of that exclusion is undertaken outside of Indigenous understandings. The validity of Hunter's (2009) arguments are borne out by research indicating that the pattern of social exclusion for Aboriginal and Torres Strait Islander people differs to that of other disadvantaged groups. For example, Saunders et al. (2007) in their examination of the extent of social exclusion find their Indigenous sample, drawn from the city of Sydney, less negatively affected by indicators of social disengagement relating to contact with others and participation in community activities. Indeed, on these indicators, the Indigenous outcomes were higher than the national figure. On indicators relating to service and economic exclusion, however, such as inability to pay utility bills, lack of emergency savings and inability to spend money on a special treat the Indigenous sample does worst.

Two conclusions can be drawn from these studies. First it is clear that social exclusion and inclusions are concepts that are resonant in the lives of urban Aboriginal people. It is also clear that the forms and shapes that social exclusion takes for Aboriginal people is not a duplicate of that other groups in Australian society traditionally associated with socio-economic disadvantage. The proportion of the Aboriginal and Torres Strait Islander population who can be regarded as socially excluded is also unclear, even from the literature that encompasses the topic. The BSL-MIAESR measure for example, estimates the prevalence of social exclusion among Indigenous Australians at more than 40 percent. However, the data for this estimate is the House- hold Income and Labour Dynamics Australia (HILDA) survey where the sample of Aboriginal and Torres Strait Islander people is small in size and groups all Aboriginal and Torres Strait Islander households into the one base 'Indigenous' category. Similarly the Social Policy Research Centre (Saunders et al., 2007) report notes that Indigenous people made up only 0.8 of their random Australian sample of 2704 community participants.

There is, therefore, despite assumptions of high levels of social exclusion among Aboriginal and Torres Strait Islander populations limited evidence to support those assumptions. The cumulative effect of limited literature, limited translatability of measures, limited evidence on the rates and types of social exclusion lead to a gap in understanding how social exclusion is maintained and sustained for Indigenous individuals, families and communities. This is especially so for the majority of Aboriginal and Torres Strait Islander people who live in urban and regional areas of Australia. As such strategies for social inclusion will also have to be tailored to meet Indigenous realities of social exclusion. To redress, at least partially, the gap in knowledge of Indigenous social exclusion, this paper uses data from the Longitudinal Study of Indigenous Children, Australia's only longitudinal Indigenous specific survey, to explore the patterns and nature of social exclusion of urban/regional Aboriginal and Torres Strait Islander families.

\section{Method/Methodology}

The Footprints in Time, Longitudinal Study of Indigenous Children (LSIC) is a national panel study that in Wave 1 (2008) surveyed the families of 1,670 Indigenous Children from 11 sites across Australia. These locations ranged from very remote communities to major capital cities (Department of Social Services, 2015). LSIC data are collected via face-to-face interviews between the Study Child's primary parent (named Parent 1) and locally employed Indigenous Research Administration Officers. Study children are divided into two cohorts; the B or baby cohort who were aged 6-18 months at Wave 1 and the $\mathrm{K}$ or kid cohort, aged 3.5-5 years at Wave 1 . The results presented in this chapter are, unless otherwise noted, drawn from Wave 6 conducted in $2013(n=1239)$ when the younger cohort was aged 5.5-7 years of age and the older cohort 8.5-10 years of age.

While not a random sample, the spread of LSIC households are similar in geographic distribution to the total Indigenous population with three quarters located in areas classified as having 'None' or 'Low' levels of remoteness and a quarter in areas deemed remote and very remote (Australian Bureau of Statistics [ABS], 2011). In Wave 6, this distribution of Parent 1 households were 28 percent in areas classified as having a remoteness level of 'None', 51 percent in 'Low', 13 percent 'moderate' and nine percent as 'high/extreme' remoteness. The sample for this study are restricted to 
those households classified as 'None' and Low' level of remoteness. In Wave 6 this results a sub-sample of 973 households. The dimensions of social exclusion explored in this study are socio-economic; household and service; Community and Health and Socio-Emotional Well-Being.

Key socio-demographic details of these households are outlined in Table 1. As shown two thirds of the families are in areas of 'Low' remoteness, most Parent 1 's are mothers and aged under forty years, although the primary carer for more than 10 percent of the children is a family member other than the child's mother.

Table 1. Study child and parent 1 demographic details: LSIC Wave 6 ( $n=973)$

\begin{tabular}{lll}
\hline Variable & Category & $\begin{array}{l}\text { Percent } \\
\%\end{array}$ \\
\hline Level of Remoteness & None & 35.4 \\
& Low & 64.6 \\
Study Child Cohort & B Younger Cohort & 58.9 \\
& K Older Cohort & 41.1 \\
Gender of Parent 1 & Male & 3.3 \\
& Female & 96.7 \\
Age of Parent 1 & $20-29$ & 24.0 \\
& $30-39$ & 47.5 \\
& $40-49$ & 21.7 \\
Indigenous Status of & Aboriginal & 6.2 \\
Parent 1 & Torres Strait Islander & 70.7 \\
& Both & 3.9 \\
Relationship of & Not Indigenous & 22.3 \\
Parent 1 to Study & Mother & 87.7 \\
Child & Father & 3.1 \\
& Grandmother & 5.9 \\
& Other female relative & 1.4 \\
\hline
\end{tabular}

\section{Socio-Economic Social Exclusion}

This correlation between Indigeniety and poverty argued by Walter (2008) is evident in the LSIC data. As shown in Table 2, 40 percent of Parent 1s, the majority of whom are mothers, were in paid work at the time of data collection, with around half of that group working full-time. This rate is significantly lower than that of non-Indigenous mothers in Australia where over two thirds of mothers of children with children aged 6-9 years are in the paid workforce (Baxter, 2009). In the free text responses to why they were not in paid work the overwhelming majority (more than 400 of the 537 responses) gave reasons related to child rearing, predominantly stating that they wanted to look after their children themselves. Only 57 respondents gave lack of employment opportunity reasons. These responses indicate a clash between Aboriginal and Torres Strait Islander primary parents' values on appropriate child rearing and the policy push for mothers receiving welfare payments to return to the workforce when or be- fore their youngest child turns six (Parenting Payment). The impact of this values differentiation is magnified given that nearly half of the Parent 1 group were unpartnered at the time of data collection.

Of those Parent 1s who were partnered, nearly 29 percent had partners not in the labour force. A small number of these were retired $(n=10)$, permanently unable to work $(n=9)$ or not well enough to work $(n=23)$ but the majority of reasons given for not being in the paid workforce related to lack of employment opportunity. Just under half of the Parent 1s reported salary or wages as their main source of income and more than 80 percent reported that Government pensions, benefits or allowances as a main source of income. Nearly two thirds of Study Child households were reported as having weekly income from all sources, after deductions, under $\$ 1000$. Unlike non-Indigenous parents therefore, who are evenly spread across the socioeconomic spectrum, for a significant proportion of LSIC parents, social exclusion as defined by economic dimensions is the norm.

Socio-economic exclusion is also evident through more objective measurements included in LSIC Wave 6 . On household deprivation measures $(n=963)$ around one third (33\%) reported that they could not pay their bills on time; nearly one in five (19\%) reported receiving assistance from a welfare organisation; pay housing

Table 2. Parent 1 socio-economic status details: LSIC Wave $6(n=973)$.

\begin{tabular}{|c|c|c|}
\hline Variable & Category & $\begin{array}{l}\text { Percent } \\
\% \\
\end{array}$ \\
\hline \multirow[t]{2}{*}{ Parent 1 Employed } & Yes & 39.7 \\
\hline & No & 60.2 \\
\hline Parent 1's & Full time & 46.8 \\
\hline Employment Type & Part time/Casual & 49.5 \\
\hline$(n=380)$ & Other & 3.7 \\
\hline Partnership Status & Unpartnered & 45.6 \\
\hline of P1 & Partnered & 54.6 \\
\hline Parent 1's Partner & Yes & 71.3 \\
\hline Employed & No & 28.7 \\
\hline Parent 1's Partner & Full-Time & 76.7 \\
\hline \multirow[t]{3}{*}{ Employment Type } & Part-time/Casual & 15.0 \\
\hline & Self Employed & 5.8 \\
\hline & Other & 2.5 \\
\hline \multirow{3}{*}{$\begin{array}{l}\text { Main Source of } \\
\text { Income* }\end{array}$} & Wages/Salary & 45.7 \\
\hline & $\begin{array}{l}\text { Govt Benefit/Pension/ } \\
\text { Allowance }\end{array}$ & 81.9 \\
\hline & $\begin{array}{l}\text { Child Support/ } \\
\text { Maintenance }\end{array}$ & 10.6 \\
\hline Household Weekly & $\$ 0-\$ 499$ & 21.2 \\
\hline Income After & $\$ 500-\$ 999$ & 41.0 \\
\hline \multirow[t]{3}{*}{ Deductions } & $\$ 1000-\$ 1499$ & 21.2 \\
\hline & $\$ 1500-\$ 1999$ & 10.8 \\
\hline & $\$ 2000$ plus & 5.6 \\
\hline
\end{tabular}

Note: ${ }^{*}$ respondents could nominate more than one nine percent could not main source of income. 


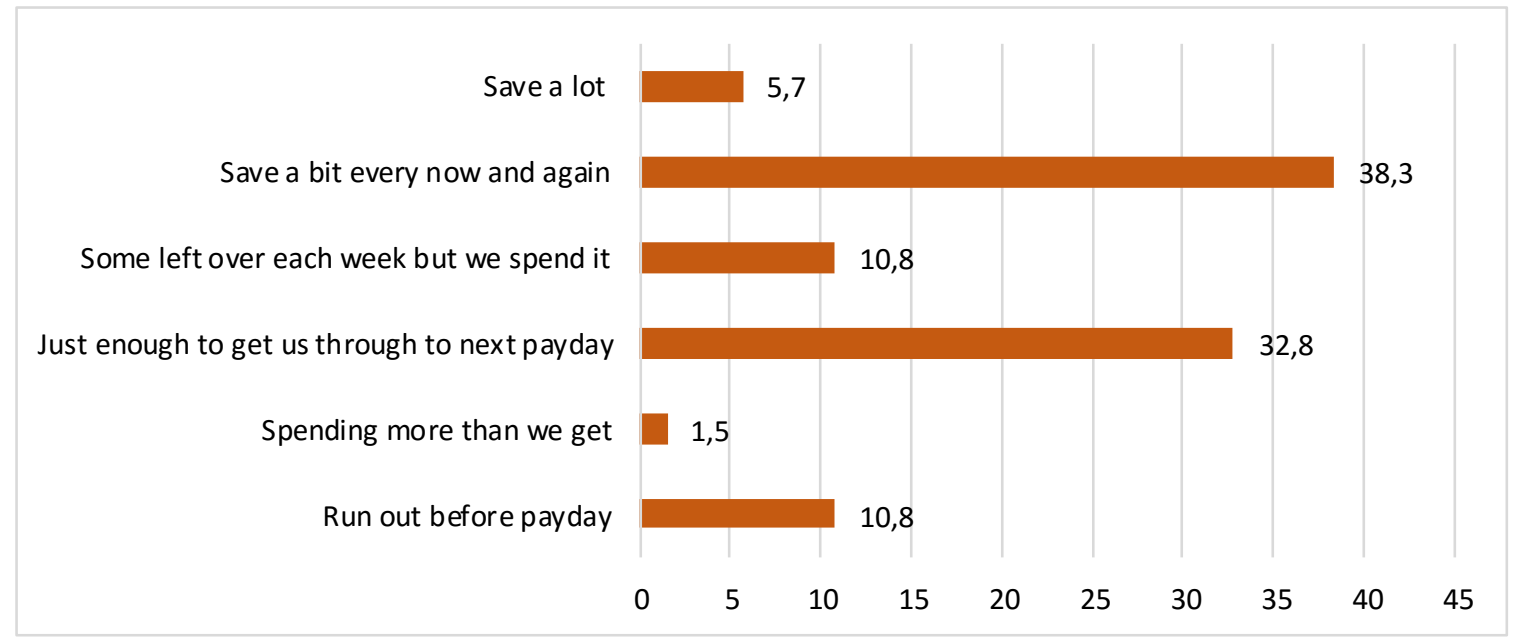

Figure 1. LSIC household self rating on financial stress (percentage).

payments in time; 12 percent had pawned or sold something to make ends meet; and around five percent respectively had been unable to heat their home, went without meals, or their child did not do school activities because of a shortage of money. On the financial hardship measures, as shown in Figure 1, despite evidence of relatively low household incomes, only 12 percent indicated they were not managing on current income and 44 percent indicated they save some money, at least some of the time. The norm of economic disadvantage within the community in which most LSIC parents live, perhaps, leads to coping money management systems that include aspects of social relationality. For example, analysis of Wave 6 data related to household meals (not shown here) finds that around 60 percent of Parent 1's report feeding people from outside of their household on a weekly or fortnightly basis.

\section{Housing/Service Social Exclusion}

The LSIC dataset capacity to measure levels of service exclusion for urban Aboriginal and Torres Strait Islander families is predominantly in the data related to housing. In line with census data (Walter, 2008) the majority of LSIC households occupy rental housing. In Wave 1 (2008) around 80 percent of households in rental accommodation with half of this group renting from public housing authorities. In consequent waves housing type was only asked of those who had moved since the previous wave. Analysis of these data (not shown here) indicate despite a small increase in the proportion paying off their home in each wave, the predominant pattern of renting remains.

The LSIC households also present a pattern of housing occupation. As shown in Table 3, around one quarter of households have more than two adults present and over 85 percent have two or more children present. In another deviation from non-Indigenous norms, 27 percent of households contain only one adult yet 46 percent of the Parent 1's report that they are unpartnered. A significant proportion of unpartnered Parent 1 households must therefore include adults who are not a partner. Walter and Hewitt (2012) confirm this likelihood, with grandmothers and sisters of the Parent 1 reported the most common adult type, other than partners, to reside in the LSIC household.

A substantial proportion (34\%) of Parent 1 households also report their housing as in need of substantial repair as also shown in Table 3. Responses to 18 discrete categories show the most common major repairs needed are: plumbing in baths and showers (5.2\%); structural problems (5.3\%); major electrical problems $(5.2 \%)$ or other major problem (6.2\%). Further analysis of these data found housing repair inadequacy was clustered with the more than 15 percent of households reporting more than one major repair was needed.

Table 3. Study child's household (Wave $6 \mathrm{n}=973$ ).

\begin{tabular}{lll}
\hline Variable & Category & $\begin{array}{l}\text { Percent } \\
\%\end{array}$ \\
\hline Housing Type & Rental Public/Community & 37.8 \\
(n=240)* & Rental Private & 47.2 \\
& Owned (mortgage/outright) & 10.5 \\
& Other & 4.5 \\
Number of Adults & One & 27.5 \\
in Household & Two & 47.5 \\
& Three & 15.3 \\
Number of & Four or more & 9.6 \\
Children in & One & 12.6 \\
Household & Three & 26.1 \\
& Four or more & 30.5 \\
Household needs & No & 23.0 \\
Major Repairs & One major Repair & 66.4 \\
& Two major repairs & 17.8 \\
& Three or more major repairs 8.3 \\
\hline
\end{tabular}

Note: * Only asked of those who moved house between Wave 5 and Wave 6. 


\section{Community Social Exclusion}

Community social exclusion is assessed through analysis of Wave 6 neighbourhood and community data. As shown in Table 4, community safety was rated relatively highly by Parent 1 with 70 percent rating their community as good or very good for little kids and nearly two thirds rated overall safety of the community as very safe of quite safe. These findings, given the level of socio-economic deprivation and high level of rental accommodation among the LSIC families indicate that other factors are the main influence on respondents understanding of why a community is safe or good for little kids.

\section{Well-Being Social Exclusion}

As shown in Table 5 , in Wave $6(n=973)$ that more than 80 percent of Parent 1's rate their own health as excellent or very good. Close to three quarters of Parent 1s, however, report that they have at least some problems in their life. Regardless, more than 80 percent of respondents stated that they were coping fairly well, very well or extremely well, indicating a substantial level of resilience, despite the socio-economic adversity they face.

Racism is also an indicator social exclusion for urban Aboriginal and Torres Strait Islander families. The results from LSIC Wave 5 racism related question find over 60 percent of Parent 1s indicated that racism was never or hardly ever an experience for them. Nearly 40 percent, however, reported experiences of racism. Cultural experiences are also a common factor in the LSIC families. In Wave 1 the cultural activity questions were asked about the Study Child rather than Parent 1. Analysis of these data show that although few urban Study Children speak an Indigenous language (4\%), two thirds were regularly taken to cultural events.

\section{How Social Exclusion Dimensions are Spread between Households}

The results in the previous sections show the incidence of different social exclusion measures in Parent 1 households. The next question is whether experience of different types of social exclusion are also clustered. Table 6 displays the results of inter-dimension correlations which show significant correlations. As can be seen, with the exception of 'P1 feels their life is difficult at present' and 'community safety' there is a statistically significant correlation of varying strengths between each dimension of social exclusion and all other dimensions. These results indicate that there is a relationship between the level of social exclusion on one measure and the level reported on others. Those with higher levels of exclusion on the individual measures are also more likely to have higher measures on other dimensions. Similarly, those with lower levels on exclusion on one measure are also more likely to record lower levels of exclusion on others.

Table 4. Parent 1 community safety ratings (wave $6, n=973$ ).

\begin{tabular}{llllll}
\hline Variable & Parent 1 Rating \% & & & \\
\hline \multirow{3}{*}{ Good community for little kids } & Very good \% & Good \% & Okay \% & Not so good \% & Really bad \% \\
& 38.5 & 31.7 & 19.8 & 7.6 & 2.4 \\
& Very Safe \% & Quite safe \% & Okay \% & Not very Safe \% & Dangerous \% \\
Overall Safety of Community & 22.3 & 40.2 & 26.7 & 9.4 & 1.3 \\
\hline
\end{tabular}

Table 5. Parent 1 social and emotional well-being measures.

\begin{tabular}{|c|c|c|c|c|}
\hline \multirow[t]{2}{*}{ Variable } & \multicolumn{4}{|c|}{ Parent 1 Rating } \\
\hline & Excellent \% & Very Good \% & Good \% & Fair/Poor \% \\
\hline \multirow[t]{3}{*}{ Parent 1 Global Health Measure (Wave 6: $n=973$ ) } & 41.0 & 39.2 & 17.3 & 3.1 \\
\hline & No problems & Few problems & Some problems & s Many/Very \\
\hline & $\%$ & $\%$ & $\%$ & many problems \\
\hline \multirow[t]{2}{*}{ Feels their life is difficult at present (Wave 6: $n=970$ ) } & 27.3 & 38.1 & 26.7 & 8.0 \\
\hline & Not at all \% & A little \% & Fairly Well \% & $\begin{array}{l}\text { Very/Extremely } \\
\text { well \% }\end{array}$ \\
\hline \multirow[t]{2}{*}{ Thinks they are coping (Wave 6: $n=970$ ) } & 0.9 & 6.8 & 42.4 & 40.8 \\
\hline & Every day \% & $\begin{array}{l}\text { Every week/ } \\
\text { Sometimes \% }\end{array}$ & Occasionally \% & $\begin{array}{l}\text { Never or hardly } \\
\text { ever \% }\end{array}$ \\
\hline \multirow{2}{*}{$\begin{array}{l}\text { Family experiences racism, discrimination or prejudice } \\
\text { (Wave } 5: n=970)\end{array}$} & 3.1 & 19.3 & 15.4 & 61.3 \\
\hline & Very often $\%$ & Often \% & Occasionally \% & Never \% \\
\hline $\begin{array}{l}\text { How often Study Child goes to Indigenous cultural } \\
\text { event (Wave 1: } n=1252 \text { ) }\end{array}$ & 7.6 & 14.8 & 41.8 & 36.2 \\
\hline
\end{tabular}


Table 6. Correlations between social exclusion measures.

\begin{tabular}{|c|c|c|c|c|c|c|}
\hline & & $\begin{array}{l}\text { P1 global } \\
\text { health } \\
\text { measure }\end{array}$ & $\begin{array}{l}\text { Major repairs } \\
\text { needed to } \\
\text { house } \\
\text { summary } \\
\text { number }\end{array}$ & $\begin{array}{l}\text { Safe } \\
\text { community }\end{array}$ & $\begin{array}{l}\text { Family money } \\
\text { situation }\end{array}$ & $\begin{array}{l}\text { P1 feels their } \\
\text { life is difficult } \\
\text { at present }\end{array}$ \\
\hline \multirow{3}{*}{$\begin{array}{l}\text { P1 global health } \\
\text { measure }\end{array}$} & Pearson Correlation & 1 & $.107^{* *}$ & $.069^{*}$ & $-.155^{* *}$ & $.232^{* *}$ \\
\hline & Sig. (2-tailed) & & .001 & .032 & .000 & .000 \\
\hline & $\mathrm{N}$ & 973 & 972 & 963 & 969 & 969 \\
\hline \multirow{3}{*}{$\begin{array}{l}\text { Major repairs } \\
\text { needed to house } \\
\text { summary number }\end{array}$} & Pearson Correlation & $.107^{* *}$ & 1 & $.073^{*}$ & $-.127^{* *}$ & $.118^{* *}$ \\
\hline & Sig. (2-tailed) & .001 & & .023 & .000 & .000 \\
\hline & $\mathrm{N}$ & 972 & 972 & 963 & 969 & 968 \\
\hline \multirow[t]{3}{*}{ Safe community } & Pearson Correlation & $.069^{*}$ & $.073^{*}$ & 1 & $-.124^{* *}$ & .009 \\
\hline & Sig. (2-tailed) & .032 & .023 & & .000 & .781 \\
\hline & $\mathrm{N}$ & 963 & 963 & 963 & 960 & 959 \\
\hline \multirow{3}{*}{$\begin{array}{l}\text { Family money } \\
\text { situation }\end{array}$} & Pearson Correlation & $-.155^{* *}$ & $-.127^{* *}$ & $-.124^{* *}$ & 1 & $-.194^{* *}$ \\
\hline & Sig. (2-tailed) & .000 & .000 & .000 & & .000 \\
\hline & $\mathrm{N}$ & 969 & 969 & 960 & 969 & 965 \\
\hline \multirow{3}{*}{$\begin{array}{l}\text { P1 feels their life } \\
\text { is difficult at } \\
\text { present }\end{array}$} & Pearson Correlation & $.232^{* *}$ & $.118^{* *}$ & .009 & $-.194^{* *}$ & 1 \\
\hline & Sig. (2-tailed) & .000 & .000 & .781 & .000 & \\
\hline & $\mathrm{N}$ & 969 & 968 & 959 & 965 & 969 \\
\hline
\end{tabular}

\section{Discussion and Conclusion}

The first task of this paper was to explore patterns of social exclusion across social, economic, neighbourhood and well-being dimensions for urban and regional Aboriginal and Torres Strait families. The socioeconomic data point to high rates of socio-economic exclusion. Low rates labour market activity, high rates of sole parenthood; high rates of rental housing and a substantial minority with inadequate housing due to disrepair. These measures all support the conclusion that LSIC households are likely to be among the poorest of households within their neighbourhoods. This finding aligns with Biddle's (2013) finding that, Australia wide, there was not a single Census area where the Indigenous populations has better or even relatively equal outcomes compared to the non-Indigenous population.

On the social participatory aspects the results are not as clear cut. The LSIC households are likely to be multiple person households with a majority rating their community as safe. A majority of Parent 1 s are also physically and socio-emotionally able. Also, a substantial minority of Parent 1's report the experience of racism and two thirds of Study Children regularly attend Indigenous cultural events, signifying cultural and racial elements remain strongly evident in household's lived experience. The correlation results indicate there is a significant overlap in those experiencing poorer outcomes across measures social exclusions. The central finding of these results, therefore, is that, in line with Saunders et al. (2007) that evidence of 'deep' social exclusion across dimensions is present, but for an, albeit substantial, minority of LSIC households. What nearly all LSIC households share, however, is significant levels of socioeconomic exclusion.
The next task of this paper is to explore the processes that create and sustain this social exclusion. That Aboriginal and Torres Strait families are socio-economically excluded is central to these processes, not because of its own inherent dimensions but as a stark reflector of social inequality. The first process, therefore, is the continued widespread exclusion of the LSIC families from mainstream economic, social, cultural and human capital resources of Australian society. This socio-economic exclusion is also socio-economic exclusion experienced within mainstream Australian urban and regional social settings. Identifying the economic correlates therefore does not do justice to the complexity this social exclusion. Social exclusion, as a concept, is culturally, socially and economically not the same for Aboriginal and Torres Strait Islander people as it is for non-Indigenous populations, in Australia or elsewhere.

The patterns shown in this research are, as argued by Lister (2004) and Sen (2000) are social structural; the results of social processes. Moreover, this inequality is racialised and directly related to the history and contemporary realities of black-white relations in Australia. The substantial proportion of urban/regional households who reported the experience of racial discrimination underscores the racialised nature of Indigenous inequality. Indigeneity is the central core, with other aspects intimately interwoven and interpreted through that Indigeneity (Walter, 2009). For example, as argued by Hunter (2000) and Walter (2015), the link between Indigenous unemployment and social exclusion is not clear in its causal direction. Are Indigenous people socio-economically excluded because they are unemployed or are Indigenous unemployment rates a consequence of broader social exclusion? The patterns of Indigenous/non-Indigenous unemployment from 
across Australia, where Indigenous rates are always multiples those of the non-Indigenous population suggest the second explanation (Walter, 2008). For example, 2011 Census data show Aboriginal unemployment rates as 18 per cent in the regional town of Dubbo and 17 per cent in the city of Perth compared to less than five percent for the non-Indigenous population both sites.

The second related process is that Indigenous socioeconomic exclusion, as a lived reality, is also different. As Hunter (1999) established, material deprivation and living in overcrowded conditions are found even among relatively high income Indigenous households. Aboriginal material well-being is also different. Even for households with higher incomes these data are not necessarily an indicator of life-course advantage (Walter \& Saggers, 2007). Such higher income is more likely to be a temporary phenomenon for Indigenous families. An analysis of the job descriptions of LSIC Parent 1s (Walter, 2015), finds at least one quarter are in Indigenous specific roles, such as community worker. Loss of that employment will likely lead directly back to low income, rather than another job at similar or higher wages. It is these two processes that determine the opportunities and the challenges of moving to greater social inclusion for urban/regional Aboriginal and Torres Strait Islander families. The deeply embedded, well-documented, long term nature of Indigenous socio-economic social exclusion suggest there is, first, no easy answer and second, that what policies have been implemented to date have been unsuccessful.

The work of Sen (2000) offers a way forward. Critical words in Sen's prescription for a minimally decent life are 'freedom to achieve' or opportunity freedom. These words denote both agency and the notion that freedom of choice is of, in itself a central aspect of capability and functioning. Without the ability to participate, in a way that is valued, in social, economic and political actions an individual or group does not have agency. Also critical is Sen's focus on the definition of a 'good life' not being determined by others but rather is about achieving the functionings to live a life that is valued by the person. As Hunter (2009) notes, social inclusion in whatever form it takes needs to include Indigenous perspectives in policies and programs as well as the promotion of full and effective participation in decisions that affect Indigenous people.

How then do current social inclusion aligned policies promote Indigenous agency to participate, in a way that is valued by Aboriginal and Torres Strait Islander people? The answer is, predominantly, that they do not. For example in the 2015 Closing the Gap Report Prime Minister Abbott, while expressing disappointment that in this $7^{\text {th }}$ annual report, little progress had been achieved, began his message by stating ' it is hard to be numerate without attending school, it's hard to find work without basic education, and hard to live well without a job'. The failure of the Government to achieve progress, there- fore, is framed immediately, on the opening page, through a discourse of individual Aboriginal failure. The long-standing, overwhelming social and societal pattern of Indigenous disadvantage and social exclusion is elided. Rather, failure of policy is linked tightly to discourses individual inadequacy and agency is implied as being negatively used by Aboriginal and Torres Strait Islander people to not make the choices they 'should'. The values here are not reflective of, or seemingly interested in, the values of the peoples to which the Closing the gap policy is being applied. They are also seemingly developed through a worldview of Indigenous people in Australia as incapable of living a decent life.

How might Indigenous policy look if a capability approach was applied? If social inclusion is interpreted as supporting the freedom to achieve the capability to live a decent life? Two criteria need to be in place. First, capability needs to be defined as socially relational, not instrumental. As argued earlier, the concept of social relationality recognises that urban Indigenous people are more than a group of disadvantaged individuals with a shared racial heritage. Aboriginal and/or Torres Strait Islander identity and culture shapes worldviews, understanding of social place and space and relationships with others. The correlation of Indigeneity and a reduced capacity to access social, economic, cultural and political resources (Walter, 2008) is intertwined within social relationality. Setting goals for individuals is unlikely to lead to increased social inclusion.

Second, strategies to increase social inclusion need to be based on Indigenous interpretations of a decent life. Sen's (2000) core functionings of being healthy, having a good job, safety and self-respect still apply, but within an Indigenous socially relational framework. The functionings of safety and self-respect, for example, exist within a social environment in which exposure to racism is a common experience. Being healthy is inclusive of social and emotional well-being which in turn is intimately related to connected to community, culture and country. Maintaining and sustaining cultural connections, as shown in these data, remains a core functioning for urban Indigenous people. Functionings around raising happy healthy children are, as shown by the data presented here, are shaped by values around mothering that differ from the dominant norms of an early maternal return to the labour market.

Would an Indigenous policy environment based on an Indigenous socially relational understanding of Sen's Capability Approach deliver better social inclusion outcomes for Aboriginal and Torres Strait Islander people? It has not been tried so no claims on its efficacy can be made. However, the current policy directions have been demonstrated, again and again, to be ineffective in social inclusion terms and probably doing more harm than good. Adopting an Indigenized Capability Approach requires a radical change of mindset from nonIndigenous politicians and policy makers. 


\section{Conflict of Interests}

The author declares no conflict of interests.

\section{References}

Australian Bureau of Statistics. (2011). Position paper: $A B S$ review of counting the homeless methodology (Aug 2011 Cat No. 2050.0.55.002). Canberra: Australian Bureau of Statistics.

Azpitarte, F., \& Bowman, D. (2015). Social exclusion monitor bulletin. Melbourne: Brotherhood of St Laurence and Melbourne Institute of Applied Economic and Social Research, University of Melbourne.

Baxter, B. (2009). 'Mothers' timing of return to work by leave use and pre-birth job characteristics. Journal of Family Studies, 15(2), 153-166.

Biddle, N. (2013). CAEPR indigenous population project: 2011 census papers, No 13/2013. Canberra: Centre for Aboriginal Economic Policy Research, Australian National University.

Bradshaw, J. (2003). How has the notion of social exclusion developed in the European discourse? Plenary address to the 2003 Australian Social Policy conference, Social Policy Research Centre, University of New South Wales, Sydney.

Brotherhood of St Laurence. (2015). Social exclusion monitor. Retrieved from https://www.bsl.org.au/ knowledge/social-exclusion-monitor

Burchardt, T., Le Grand, J., \& Piachaud, D. (2002). Introduction. In T. Burchardt, J. Le Grand, \& D. Piachaud (Eds.), Social exclusion. Oxford: Oxford University Press.

Department of Families, Housing, Community Services and Indigenous Affairs. (2011). Footprints in time: The longitudinal study of indigenous children. Key summary report from wave 2. Canberra: Department of Families, Housing, Community Services and Indigenous Affairs.

Department of Social Services. (2015). Footprints in time: The longitudinal study of indigenous children wave 5 . Canberra: Department of Social Services.

Fincher, R., \& Saunders, P. (2001). Creating unequal futures? Rethinking inequality, poverty and disadvantage. Sydney: Allen \& Unwin.

Gordon, D., Adelman, L., Ashworth, K., Bradshaw, J., Levitas, R., Middleton, S., . . . Williams, J. (2000). Poverty and social exclusion in Britain. York: Joseph Rowntree Foundation.

Hunter, B. (1999). Three nations not one: Indigenous and other Australian poverty (CAEPR, working paper no. 1). Canberra: Australian National University.

Hunter, B. (2000). Social exclusion, social capital and Indigenous Australians: Measuring the social costs of unemployment (Discussion Paper No. 204). Canberra: Centre for Aboriginal Economic Policy Research, The Australian National University.

Hunter, B. (2009). Indigenous social exclusion: Insights and chgallenges for the concept of social inclusion. Family Matters, 82, 52-61.

Lister, R. (2004). Poverty. Cambridge: Polity Press.

Saunders, P. (2003). Can social exclusion provide a new framework for measuring poverty? (SPRC discussion paper no. 127). Sydney: Social Policy Research Centre, University of New South Wales.

Saunders, P., Naidoo, Y., \& Griffiths, M. (2007). Towards new indicators of disadvantage: Deprivation and social exclusion in Australia. Sydney: Social Policy Research Centre, University of New South Wales.

Sen, A. (2000). Social exclusion: Concept, application and scrutiny (Social Development Papers No. 1). Manila: Asian Development Bank.

Steering Committee for the Review of Government Service Provision. (2014). Overcoming Indigenous disadvantage: Key indicators. Canberra: Steering Committee for the Review of Government Services Provision, Productivity Commission.

Walter, M. (2008). Lives of diversity: Indigenous Australians (Occasional paper 4/2008, Census Series\#2). Canberra: Australian Academy of the Social Sciences.

Walter, M. (2009). An economy of poverty: Power and the domain of aboriginality. International Journal of Critical Indigenous Studies, 2(1), 2-14.

Walter, M. (2015). The vexed relationship between social mobility and social capital for aboriginal and Torres Strait Islander People. Australian Journal of Social Issues, 50, 69-88.

Walter, M., \& Hewitt, B. (2012). Post separation parenting and indigenous families. Family Matters, 91, 83-91.

Walter, M., \& Saggers, S. (2007). Poverty and social class. In B. Carson, T. Dunbar, R. Chenhall \& R. Bailie (Eds.), Social determinants of indigenous health (pp. 87104). Crows Nest: Allen and Unwin.

\section{About the Author}

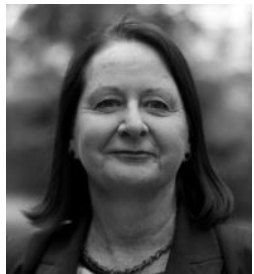

Dr. Maggie Walter

Maggie Walter (PhD) descends from the parerebeenne people of tebrekunna country in North Eastern Tasmania. She is Professor of Sociology and the inaugural Pro Vice-Chancellor of Aboriginal Research and Leadership at the University of Tasmania. She is a long term member of the steering committee of the Longitudinal Study of Indigenous Children and has published extensively in the field of race relations, inequality and research methods and methodologies. 